\title{
Genetic and environmental parameters for ewe productivity in Merinos
}

\author{
G. Duguma ${ }^{1 *}$, S.J. Schoeman ${ }^{1, \#}$, S.W.P. Cloete ${ }^{2}$ and G.F. Jordaan ${ }^{1}$ \\ ${ }^{1}$ Department of Animal Sciences, University of Stellenbosch, P. Bag X1, Matieland 7602, South Africa \\ ${ }^{2}$ Elsenburg Agricultural Research Centre, P. Bag X1, Elsenburg 7607, South Africa
}

\begin{abstract}
Data of 3272 lambing records collected on 818 ewes born from 689 dams and sired by 371 rams were used in the evaluation of ewe lifetime productivity (total number born, number weaned and total weight weaned). These records were collected from ewes born from 1969 to 1994 and which gave birth during the period from 1971 to 1999. Year of birth of ewe and ewe two-tooth liveweight affected the ewe productive traits investigated. Multiple born ewes were superior both in total number of lambs born and weaned compared to singles. Heritability estimates of $0.23,0.17$ and 0.20 were obtained for total number of lambs born (TLB), total number of lambs weaned (TLW) and total weight of lamb weaned per ewe over four lambing opportunities (TWW), respectively. For total weight weaned per ewe over the first lambing opportunity (TWW1) a heritability of 0.02 was estimated. Genetic correlation estimates of $-0.10,0.57$ and 1.00 were obtained between TWW1 and TLB, TWW1 and TLW and TWW1 and TWW, respectively. High and positive genetic correlations ranging from 0.61 to 0.92 were estimated between ewe lifetime traits. Genetic progress could be expected when selection is applied on these traits.
\end{abstract}

Keywords: Ewe productivity, heritability, genetic correlations

${ }^{\#}$ Corresponding author. E-mail address: sjsc@sun.ac.za

*Present address: Bako Agricultural Research Centre, P.O. Box 3, West Shoa, Bako, Ethiopia

\section{Introduction}

Improved ewe productivity is a major objective in the local sheep industry. This could be achieved in part by increasing the number of lambs weaned and weight of lambs weaned per ewe per year. These traits are important since most sheep are raised for mutton production. In South Africa, though Merino sheep are pre-eminently wool producers, 50 to $60 \%$ of the income is generated through mutton or lamb production (Snyman et al., 1998b). Schoeman (2000) reported that sheep production, which was until recently primarily aimed towards wool production, has changed owing to inter alia the high demand for mutton and lamb, the meat $v s$. wool price structure and input costs.

Until recently emphasis has mostly been placed on the individual component traits of reproduction such as fertility, litter size, lamb survival rate and the number of lambs born and weaned per ewe joined. Ewe productivity, defined as the number or total weight of lamb weaned per ewe joined, which comprises of several component traits (Fogarty et al., 1985), has received much less attention (Fogarty, 1995) and only a few genetic parameter estimates are available.

The total weight of lamb weaned per year is the best single measure of a flock's productivity (Snyman et al., 1997). It is a function of the number of lambs born, their survival and the individual lamb weight at weaning (Boujenane et al., 1991). According to Snyman et al. (1997), there is relatively large phenotypic variation in total weight of lamb weaned regardless of the reproductive rate of the flock. They indicated that this variation may have a genetic basis and could, therefore, be exploited to genetically increase lifetime reproductive efficiency in any flock. Selection for total weight of lamb weaned would result in a correlated genetic increase in weaning weight of individual lambs (Olivier et al., 2001). Total weight of lamb weaned is determined by litter size as well as several other factors, such as mothering ability, milk production of the ewe and the growth potential of the lamb (Snyman et al., 1997).

The objective of this study was to estimate genetic parameters for ewe lifetime productivity in the Merino flock at the Tygerhoek Experimental Farm. Genetic correlations between total weight weaned in the first parity and total lifetime production of ewes were also investigated. Estimation of genetic correlations between total weight weaned in the first parity and total lifetime production so as to make either early culling or selection decisions are prerequisites for maximising production efficacy. 


\section{Materials and Methods}

Lifetime production records for number of lambs born, number of lambs weaned and weight of lambs weaned were studied in the Merino flock at the Tygerhoek Experimental Farm. After editing, 818 ewes with 3272 lambing opportunities from 1971 to 1999 were used. Over the four parities 4279 lambs were born and 3328 weaned. In 493 cases (or $15 \%$ of those having an opportunity to wean lambs) no lambs were weaned. The ewes were the progeny of 689 dams and 371 sires. The traits studied were total number of lambs born per ewe over four lambing opportunities (TLB), total number of lambs weaned per ewe over four lambing opportunities (TLW) and total weight of lamb weaned per ewe over four lambing opportunities (TWW) and total weight of lamb weaned per ewe at first parity (TWW1). The first four lambing opportunities of an ewe were used to indicate lifetime reproduction. Thus, only data of ewes with four consecutive lambing opportunities (only those ewes which have the opportunities to give birth for four consecutive lambings) were used in this analysis. All ewes were bred to lamb for the first time at 2-yr of age. In all cases, ewe ages ranged from 2 to 6 years.

Total weight of lamb weaned for each ewe was computed by adding sex adjusted weaning weights of all the lambs weaned by the ewe in a specific lambing year. Total weaning weight over four consecutive lambing opportunities was calculated by adding the total weight of lambs weaned per ewe for the first, second, third and fourth lambing seasons. Weaning weight of lambs was recorded at about 120 days of age from 1970 to 1982 and at about 100 days of age thereafter, and it was adjusted accordingly.

The traits, TLB and TLW were considered as continuous for this study. This was justified because these traits were a combination of four separate lambings, which increased the number of categories.

Different models for analysing the data were used, depending on the parameters being estimated. The General Linear Models of SAS (1996) were used in the initial analyses of the data to determine the contribution of fixed effects on ewe productivity. The operational model for the analyses included only those effects having an influence $(\mathrm{P}<0.05)$. For TLB and TLW ewe birth type and ewe birth year were included, while for TWW, ewe birth year was fitted as the only significant $(\mathrm{P}<0.01)$ fixed effect. The model of analysis for TWW1 included group (selection and control group), ewe birth year and birth type of the ewe (single or multiple) as fixed effects. In all cases, ewe two-tooth liveweight was fitted as a covariable. Variance components for ewe productivity were estimated by Restricted Maximum Likelihood procedures (REML) applying the VCE 4.2.5 package of Groeneveld (1998). An animal model, including random additive animal effects was used to estimate variance components. Initially, the maternal genetic effect was also fitted as an additional random effect with that of the direct genetic effect. However, it was estimated as zero in all cases, thus only the model with the direct genetic effect was used. By using the estimated variance components, direct heritabilities $\left(\mathrm{h}^{2}\right)$ were computed. Following completion of the unitrait analysis, a series of two-trait pairwise analyses were conducted to estimate the genetic correlations between traits.

The model fitted was:

$\begin{array}{cl}\mathrm{Y}=\mathrm{Xb}+\mathrm{Za}+\mathbf{e} & \\ \text { where } & \\ \mathbf{y} & =\text { vector of observations } \\ \mathbf{b} & =\text { vector of fixed effects } \\ \mathbf{a} & =\text { vector of random animal effects } \\ \mathrm{X} & =\text { the matrix that associates } \mathbf{b} \text { with } \mathrm{Y} \\ \mathrm{Z} & =\text { the matrix that associates } \mathbf{a} \text { with } \mathrm{Y} \\ \mathbf{e} & =\text { vector of random residual effects. }\end{array}$

\section{Results}

The overall means and significance of the fixed effects for productivity traits are shown in Table 1 . Least squares means for TLB, TLW and TWW1 are also presented in Table 2. The fixed models accounted for $14.4 \%$ and $17.5 \%$ of the variances in TLB and TLW and for $13.9 \%$ in TWW, respectively. It accounted for $40.5 \%$ of the variance in TWW1. Of the different effects considered, two-tooth liveweight of the ewe was of paramount importance for all four traits, followed by ewe type of birth for TLB and TLW (Table 1).

The regression of ewe lifetime productivity on two-tooth ewe liveweight and ewe birth year were significant $(\mathrm{P}<0.01)$ in all productivity traits considered (Tables 1$)$. Selection group (selection or control group) also had a significant $(\mathrm{P}<0.01)$ effect on TWW1 (Table 2). Ewes that were born as multiples lambed $7.6 \%(0.40 \mathrm{lambs})$ and weaned $7.4 \%$ (0.30 lambs) more lambs over four opportunities than their single born 
contemporaries (Table 2). Multiple bearing ewes weaned $22.3 \%(5.4 \mathrm{~kg}$ ) more weight of lambs than those ewes which gave birth to singles. Ewes from the group selected for clean fleece weight were by $6.2 \%$ (1.5 $\mathrm{kg}$ ) higher in TWW1 than for ewes in the control group.

Table 1 Overall means, coefficients of variation (\%) and significance of fixed effects for total number of lambs born (TLB), total number of lambs weaned (TLW), total weight of lambs weaned over four consecutive parities (TWW) and total weight of lamb weaned in the first parity (TWW1)

\begin{tabular}{lcccc}
\hline Variables & \multicolumn{4}{c}{ Traits } \\
\hline & TLB & TLW & TWW & TWW1 \\
Overall mean & (n) & $(\mathrm{n})$ & $(\mathrm{kg})$ & $(\mathrm{kg})$ \\
CV $(\%)$ & 5.2 & 4.1 & 92.6 & 24.3 \\
Ewe birth year & 19.4 & 28.2 & 29.1 & 22.7 \\
Ewe birth type & $*$ & $*$ & $*$ & $*$ \\
Birth type of lambs & $*$ & $*$ & $\mathrm{NS}$ & $\mathrm{NS}$ \\
Ewe two-tooth liveweight & - & - & - & $*$ \\
Selection group & $*$ & $*$ & $*$ & $*$ \\
$\mathrm{R}^{2}$ model (\%) & $\mathrm{NS}$ & $\mathrm{NS}$ & $\mathrm{NS}$ & $*$ \\
\hline
\end{tabular}

Table 2 Least squares means $( \pm$ s.e. $)$ for the significant $(\mathrm{P}<0.01)$ fixed effects of total number of lambs born (TLB), total number of lambs weaned (TLW) and total weight of lambs weaned at the first parity (TWW1)

\begin{tabular}{lccc}
\hline Fixed effects & TLB & TLW & TWW1 \\
\hline Ewe type of birth & & & \\
Single & $5.1 \pm 0.05$ & $4.0 \pm 0.06$ & \\
Multiple & $5.5 \pm 0.07$ & $4.3 \pm 0.07$ & \\
Group & & & \\
Fleece Weight + & & & $27.9 \pm 1.37$ \\
$\quad$ Control & & & $26.4 \pm 1.36$ \\
Type of lambing & & & \\
Single & & & $23.6 \pm 0.27$ \\
Multiple & & $29.0 \pm 0.56$ \\
\hline
\end{tabular}

Estimates of variance components and direct heritabilities are presented in Table 3 and estimated genetic correlations among the different traits are presented in Table 4. Standard errors of heritability estimates ranged form 0.06 to 0.07 . For possible comparisons, published heritability estimates for total number of lambs born, lambs weaned and total weight of lambs weaned per ewe lifetime production are summarised in Table 5.

Table 3 Variance components and heritability estimates for total number of lambs born (TLB), total number of lambs weaned (TLW), total weight of lamb weaned (TWW) over four parities and total weight of lambs weaned in the first parity (TWW1)

\begin{tabular}{lrrrr}
\hline Trait & $\sigma^{2}{ }_{a}$ & $\sigma^{2}{ }_{e}$ & $\sigma^{2}{ }_{p}$ & $\mathrm{~h}^{2}$ \\
\hline TLB & 0.24 & 0.80 & 1.04 & 0.23 \\
TLW & 0.22 & 1.09 & 1.31 & 0.17 \\
TWW & 141.89 & 571.86 & 713.75 & 0.20 \\
TWW1 & 0.43 & 29.30 & 29.73 & 0.02 \\
\hline
\end{tabular}

$\sigma_{a}^{2}=$ additive genetic variance; $\sigma^{2}{ }_{e}=$ residual variance; $\sigma_{p}^{2}=$ phenotypic variance; $\mathrm{h}^{2}=$ direct heritability.

The estimated heritabilities for ewe lifetime productivity traits were moderate and ranged from 0.17 to 0.23 . However, the estimated heritability for TWW1 was very low $(0.02$; Table 3$)$. The estimated genetic correlations ranged from small negative to unity. The largest genetic correlation was obtained between TWW1 and TWW, while a small negative correlation $\left(\mathrm{r}_{\mathrm{g}}=-0.10\right)$ was estimated between TWW1 and TLB. 
Table 4 Genetic correlations between total number of lamb born (TLB), total number of lambs weaned (TLW), total weight of lambs weaned (TWW) over four parities and total weight of lamb weaned in the first parity (TWW1)

\begin{tabular}{llll}
\hline & TLB & TLW & TWW \\
\hline TWW1 & $-0.10 \pm 0.24$ & $0.57 \pm 0.23$ & $1.00^{*}$ \\
TLB & & $0.62 \pm 0.16$ & $0.61 \pm 0.17$ \\
TLW & & & $0.92 \pm 0.04$ \\
* standard error is not available & &
\end{tabular}

Table 5 Published heritability estimates obtained with an animal model for total number of lambs born (TLB), total lambs weaned (TLW) and total weight of lamb weaned (TWW) over $>1$ lambing opportunities

\begin{tabular}{|c|c|c|c|c|}
\hline TLB & TLW & TWW & Breed & Reference \\
\hline 0.11 & & & Rambouillet & Burfening et al. (1993) \\
\hline 0.03 & & & Border Leicester & Brash et al. (1994a) \\
\hline 0.08 & 0.04 & & Dorset & Brash et al. (1994b) \\
\hline 0.06 & 0.04 & & Corriedale & Brash et al. (1994c) \\
\hline \multirow[t]{6}{*}{0.09} & 0.04 & 0.06 & Hyfer & Fogarty et al. (1994) \\
\hline & & 0.22 & Merino & Snyman et al. (1997) \\
\hline & & 0.17 & Afrino & Snyman et al. (1997) \\
\hline & & 0.13 & Merino & Snyman et al. (1998a) \\
\hline & & 0.13 & Merino & Snyman et al. (1998c) \\
\hline & & 0.22 & Merino & Snyman et al. (1998c) \\
\hline 0.26 & 0.17 & & Afrino & Snyman et al. (1998c) \\
\hline 0.23 & 0.17 & 0.19 & Merino & Olivier et al. (2001) \\
\hline \multirow[t]{2}{*}{0.19} & 0.16 & 0.21 & Merino & Olivier et al. (2001) \\
\hline & 0.14 & 0.15 & Merino & Cloete et al. (2002) \\
\hline 0.23 & 0.17 & 0.20 & Merino & Present study \\
\hline
\end{tabular}

\section{Discussion}

The overall mean for TWW obtained in the current study was in general agreement with those reported for the Grootfontein flock over three lambing opportunities (Snyman et al., 1997; Herselman et al., 1998). Snyman et al. (1998a) reported a yearly mean of $52.4 \mathrm{~kg}$ for TWW per ewe joined calculated over three opportunities for the flock used in the current study. It has been reported that Merino ewes weaned only 37.8 to $91.1 \mathrm{~kg}$ of lambs over three lambing opportunities compared to $116.8 \mathrm{~kg}$ in the case of Afrino ewes (Herselman et al., 1998; Snyman et al., 1998a). Herselman et al. (1998) indicated that a lower reproduction rate in high fibre-producing genotypes is to be expected. Moreover, Snyman et al. (1998c) estimated negative genetic correlations ranging from -0.32 to -0.52 between clean fleece weight and reproduction traits. This suggested that increasing litter weight puts an added burden on the ewe's metabolic system and results in phenotypic decreases in fleece weight (Ercanbrack \& Knight, 1998).

Means for TLB and TLW obtained in the current study were higher than those reported for the Carnarvon Merino flock (Snyman et al., 1997). They reported 2.22 and 1.88 total number of lambs born and weaned per ewe joined over three lambing opportunities, respectively. The TLB and TLW reported in the present study accorded with results reported by Basuthakur et al. (1973) and Hall et al. (1994).

Multiple born ewes were superior to singles in both the TLB and TLW. The superiority of multiple born ewes as compared to those of singles obtained in the present study was in agreement with results reported by Cloete \& Heydenrych (1986) who used part of the same data set. It was also in accordance with results of Kritzinger et al. (1984). In the current study, ewe type of birth, however, did not affect TWW1 or TWW $(\mathrm{P}>0.05)$.

The significant influence of two-tooth ewe liveweight on productivity traits obtained, confirm an earlier suggestion by Cloete \& Heydenrych $(1986 ; 1987 b)$. They indicated that selection for an increased two-tooth ewe liveweight (at about $1.5 \mathrm{yrs}$ of age) may probably be associated with an increase in reproduction rate in Merino sheep.

Heritabilities obtained for TWW were in the range reported in most of the literature cited (Table 5) but were lower than those of the heritability estimates for individual lamb weaning weights (Duguma, 2001; $\mathrm{h}^{2}=0.29-0.40$ ). Snyman et al. (1997) reported heritabilities which varied from 0.10 to 0.26 (over three to 
four lambing opportunities). The heritability estimate of TWW1 obtained in the present study was in agreement with those reported by Snyman et al. (1997). In the Grootfontein Merino flock, Snyman et al. (1997) obtained $\mathrm{h}^{2}$ estimates of $0.08,0.05,0.13$ and 0.10 for the first, second, third and fourth lambing opportunities, respectively. Corresponding estimates were $0.09,0.17,0.22$ and 0.26 for Carnarvon Merino flock (Snyman et al., 1997).

Heritability estimates for TLB and TLW obtained in the current study were in close agreement with those reported by Olivier et al. (2001), but were higher than those reported in the literature (Table 5). Cloete \& Heydenrych (1987a) reported estimates ranging from 0.29 to 0.36 for total number of lambs born and weaned per ewe conceived over four lambings opportunities for the Tygerhoek Merino flock using half-sib analysis. Fogarty (1995) indicated that REML estimates of heritability from an animal model were lower, but might be regarded as more reliable than earlier estimates for these traits. The use of an animal model to obtain genetic parameters combines information from paternal half-sib, maternal half-sib and dam-offspring effects (Visscher \& Thompson, 1992). In his review, Fogarty (1995) reported an average lifetime heritability estimate of 0.14 for total number of lambs born per lambing opportunity using REML procedures and fitting an animal model. In general, the heritability estimates obtained in the present study indicate that there is scope for genetic improvement if selection is based on either of the traits considered.

The unity genetic correlation between TWW1 and TWW was in accordance with that reported for the Carnarvon Merino flock, but slightly higher than those reported for the Grootfontein Merino and Carnarvon Afrino flocks (Snyman et al., 1997). A high genetic correlation between TWW1 and TWW could be expected due to the fact that TWW1 forms part in the calculation of TWW. Snyman et al. (1997), who obtained similar high genetic correlations between TWW1 and TWW over different lambing opportunities, concluded that the latter trait, which is a very important, but sex limited as well as a laborious and time consuming measurement, can be improved by indirect selection for body weight at any age (Snyman et al., 1998c). The estimated genetic correlation between TLW and TWW was very high and positive. This estimate was slightly lower than those ranging from 0.97 to 0.98 reported between the same traits by Olivier et al. (2001) for the Grootfontein and the Carnarvon Merino flocks, but slightly higher than the estimate of 0.84 reported by Snyman et al. (1998c) for Afrinos. The genetic correlations obtained between TLB and TLW, TLB and TWW were lower than those reported for Afrinos (Snyman et al., 1998c). No comparable estimates between TWW1 and TLB could be found in the literature. The very low genetic correlation between these traits $(-0.10 \pm 0.24)$ indicated that selection for one of them was unlikely to affect the other. In general, the high heritabilities for and high genetic correlations obtained between these ewe lifetime productivity traits indicated that significant improvement from selection can be achieved in this flock. The high genetic correlations between TWW1 and TLW, TWW1 and TWW could also indicate that TWW1 could be used as selection criteria to indirectly improve both TLW and TWW.

\section{Conclusions}

The results of this study indicated that several non-genetic fixed factors have a significant influence on ewe productivity traits. Genetic improvement for ewe lifetime productivity would be expected from selection for either TLB, TLW or TWW. Predicting breeding values for these traits should be considered.

\section{References}

Basuthakur, A.K., Burfening, P.J. Van Horn, J.L. \& Blackwell, R.L., 1973. A study of some aspects of lifetime production in Targhee and Columbia sheep. J. Anim. Sci. 36, 813-820.

Boujenane, I., Bradford, G.E., Berger, Y.M. \& Chikhi, A., 1991. Genetic and environmental effects on growth to one year and viability of lambs from crossbreeding study of D'man and Sardi breeds. J. Anim. Sci. 69, 3989-3998.

Brash, L.D., Fogarty, N.M., Barwick, S.A. \& Gilmour, A.R., 1994a. Genetic parameters for Australian maternal and dual-purpose meat sheep breeds. I. Liveweight, wool production and reproduction in Border Leicester and related types. Aust. J. Agric. Res. 45, 459-468.

Brash, L.D., Fogarty, N.M. \& Gilmour, A.R., 1994b. Reproductive performance and genetic parameters for Australian Dorset sheep. Aust. J. Agric. Res. 45, 427-441.

Brash, L.D., Fogarty, N.M. \& Gilmour, A.R., 1994c. Genetic parameters for Australian maternal and dualpurpose meat sheep breeds. II. Liveweight, wool and reproduction in Corriedale sheep. Aust. J. Agric. Res. 45, 469-480. 
Burfening, P.J., Kachman, S.D., Hanford, K.J. \& Rossi, D., 1993. Selection for reproductive rate in Rambouillet sheep: Estimated genetic change in reproductive rate. Small Rumin. Res. 10, 317-330.

Cloete, S.W.P., Greeff, J.C. \& Lewer, R.P., 2002. Heritability estimates, genetic and phenotypic correlations of lamb production parameters with hogget live weight and fleece traits in Western Australian Merinos. Aust. J. Agric. Res. 35, 281-286.

Cloete, S.W.P. \& Heydenrych, H.J., 1986. Factors affecting reproduction in Merino ewes of the Tygerhoek Merino flock. S. Afr. J. Anim. Sci. 16, 36-42.

Cloete, S.W.P. \& Heydenrych, H.J., 1987a. Genetic parameters for reproduction rate in the Tygerhoek Merino flock. 1. Heritability. S. Afr. J. Anim. Sci. 17, 1-7.

Cloete, S.W.P. \& Heydenrych, H.J., 1987b. Genetic parameters for reproduction rate in the Tygerhoek Merino flock. 2. Genetic correlations with wool and live mass traits. S. Afr. J. Anim. Sci. 17, 8-14.

Duguma, G., 2001. A genetic study of early growth traits and ewe productivity in Merino sheep. M.Sc. Thesis, University of Stellenbosch, South Africa.

Ercanbrack, S.K. \& Knight, A.D., 1998. Responses to various selection protocols for lamb production in Rambouillet, Targhee, Columbia and Polypay sheep. J. Anim. Sci. 76, 1311-1325.

Fogarty, N.M., 1995. Genetic parameters for liveweight, fat and muscle measurements, wool production and reproduction in sheep: a review. Anim. Breed. Abstr. 63, 101-143.

Fogarty, N.M., Brash, L.D. \& Gilmour, A.R., 1994. Genetic parameters for reproduction and lamb production and their components and liveweight, fat depth and wool production in Hyfer sheep. Aust. J. Agric. Res. 45, 443-457.

Fogarty, N.M., Dickerson, G.E. \& Young, L.D., 1985. Lamb production and its components in pure breeds and composite lines. III. Genetic parameters. J. Anim. Sci. 60, 40-57.

Groeneveld, E., 1998. A multivariate multimodel REML (co) variance component estimation package. User's Guide, Version 4.2.5, D-31535, Neustadt, Germany.

Hall, D.G., Gilmour, A.R. \& Fogarty, N.M., 1994. Variation in reproduction and production of Poll Dorset ewes. Aust. J. Agric. Res. 45, 415-426.

Herselman, M.J., Olivier, J.J. \& Snyman, M.A., 1998. Studies on small ruminant breeds with inherent differences in fibre production and ewe productivity 1 . Relationship between ewe productivity and wool production potential. S. Afr. J. Anim. Sci. 28, 1-8.

Kritzinger, N.M., Stindt, H.W. \& Van der Westhuysen, J.M., 1984. Assessment of different selection criteria for reproduction rate in Dormer and SA Mutton Merino sheep. 1. Birth type and early reproductive performance of the ewe. S. Afr. J. Anim. Sci. 14, 79-83.

Olivier, W.J., Snyman, M.A., Olivier, J.J., Van Wyk, J.B. \& Erasmus, G.J., 2001. Direct and correlated responses to selection for total weight of lamb weaned in Merino sheep. S. Afr. J. Anim. Sci. 31, 115121.

SAS, 1996. SAS User's Guide, Statistics. Statistical Analysis Systems Institute, Inc., Cary, North Carolina.

Schoeman, S.J., 2000. A comparative assessment of Dorper sheep in different production environments and systems. Small Rumin. Res. 36, 137-146.

Snyman, M.A., Olivier, J.J., Erasmus, G.J. \& Van Wyk, J.B., 1997. Genetic parameter estimates for total weight of lamb weaned in Afrino and Merino sheep. Livest. Prod. Sci. 48, 111-116.

Snyman, M.A., Cloete, S.W.P. \& Olivier, J.J., 1998a. Genetic and phenotypic correlations of total weight of lamb weaned with body weight, clean fleece weight and mean fibre diameter in three South African Merino flocks. Livest. Prod. Sci. 55, 157-162.

Snyman, M.A., Erasmus, G.J. \& Van Wyk, J.B., 1998b. The possible genetic improvement of reproduction and survival rate in Afrino sheep using a threshold model. S. Afr. J. Anim. Sci. 28, 120-124.

Snyman, M.A., Erasmus, G.J., Van Wyk, J.B. \& Olivier, J.J., 1998c. Genetic and phenotypic correlations among production and reproduction traits in Afrino sheep. S. Afr. J. Anim. Sci. 28, 74-81.

Visscher, P.M. \& Thompson, R., 1992. Comparisons between genetic variances estimated from different types of relatives in dairy cattle. Anim. Prod. 55, 315-320. 